\title{
SINERGI PERGURUAN TINGGI, PERANGKAT DESA DAN LEMBAGA SOSIAL UNTUK MEWUJUDKAN DESA WISATA PETIK JERUK SELOREJO
}

\author{
Yupono Bagyo ${ }^{1}$, Amir Kusnanto ${ }^{2}$, Tachjuddin ${ }^{3}$, Sugeng Hariadi ${ }^{4}$, Siwi Dyah \\ Ratnasari $^{5}$, Dwi Daenasty Decasari ${ }^{6}$ \\ ${ }^{1}$ STIE Malangkuçeçwara Malang \\ yuponob@stie-mce.ac.id \\ ${ }^{2}$ STIE Malangkuçeçwara Malang \\ amirkusnanto@gmail.com \\ ${ }^{3}$ STIE Malangkuçeçwara Malang \\ tachjud57@yahoo.com \\ ${ }^{4}$ STIE Malangkuçeçwara Malang \\ hariadisg@yahoo.com \\ ${ }^{5}$ STIE Malangkuçeçwara Malang \\ siwiratna71@gmail.com \\ ${ }^{6}$ STIE Malangkuçeçwara Malang \\ ddwidanesty@yahoo.com \\ Web: desawisatajeruk.com \\ Youtube: https://youtu.be/J7RYGBjikCQ
}

\begin{abstract}
The majority of Selorejo villagers are farmers of citrus crops. Selorejo orange product is famous and has 12 kinds of oranges. Regent of Malang, Mr. H. Rendra Krisna expects Selorejo village to be a pilot village of citrus picking tour in Malang regency.

The problems of Selorejo Village, Malang, are: a) people are still not ready to receive tourist visit from both domestic and foreign; b) Spatial village is not yet tidy including layout of bus parking and tour vehicle; c) The need to centralize the sale of citrus and other processed citrus products; d) Assisting the empowerment of villagers with more rooms for tourists; and e) lack of promotion.

Solutions are offered 1-year IbDM Program that is a) Entrepreneurship Training, GAPOKTAN, PKK, Karang Taruna / Tour manager; b) Map of Citrus Tourist Sites; c) Making citrus kiosks and village superior products; d) Clean the sewer from plastic waste; e) Website Creation; f) Making of drainage in citrus hut; and g) Making of citrus hut.
\end{abstract}


The method of implementation in achieving the specific objectives of the IbDM Program is in accordance with the needs of the villagers of Selorejo, the Implementing Team conducts training to GAPOKTA, PKK, Tour Manager / Karang Taruna, including entrepreneurship training, marketing, accounting. In addition, the team implements the implementation of science and technology in the form of website creation, and improvement of tourism infrastructure facilities.

Achievements of 1 st year IbDM program activities are: a) Prime Service Training, Entrepreneurship and Accounting for GAPOKTAN, PKK, Tour Manager / Karang Taruna; b) Map of Citrus Tourist Sites; c) Create a Gazebo for the marketing of the Village's Featured Products; d) Website Creation; e) Making drains in citrus huts; and f) Making of citrus hut. So $100 \%$ of 1 year IbDM program has been implemented.

Keywords: Selorejo Village, Petuk Jeruk

\section{Pendahuluan}

Mayoritas penduduk Desa Selorejo adalah sebagai petani tanaman jeruk. Produk jeruk Selorejo sudah terkenal dan memiliki 12 macam jenis jeruk. Saat ini semakin banyak penduduk yang menanam jeruk, karenanya harapan pernah diungkapkan Bupati Malang Bapak H. Rendra Krisna yang ditulis di Malang Pos tgl. 1 Mei 2014, bahwa "wisata petik jeruk berdampak positif terhadap perkembangan petani jeruk dan potensi yang ada, khususnya yang ada di desa wisata Selorejo. Dan desa Selorejo akan menjadi desa percontohan wisata petik jeruk di Kabupaten Malang seperti halnya yang dapat dikembangkan di daerah Poncokusumo, daerah Karangploso dan beberapa daerah lainnya".

Masyarakat yang mengunjungi desa Selorejo untuk memetik jeruk akan dikenakan biaya Rp. 15.000 setiap orang dan bisa makan jeruk sepuasnya di lokasi kebun. Jika ingin membeli jeruk untuk oleh-oleh bisa membeli dengan harga Rp. 5.000-Rp. 7.000 per kg untuk jeruk manis dan Rp. 12.000 - Rp. 15.000 per kg untuk jeruk keprok.

\section{Peta Lokasi dan Denah}

Desa Selorejo terletak di Kecamatan Dau, Kabupaten Malang, Jawa Timur, merupakan desa yang memiliki potensi besar agro '32’46 wisata. Desa Selorejo secara astronomis terletak pada 756'19.70" lintang selatan dan 112.65 bujur timur. Lokasinya sekitar 13 km dari Kampus STIE Malangkuçeçwara.

Topografi Desa Selorejo tergolong dataran tinggi dengan luas perbukitan seluas 333,76 ha. Ketinggian Desa Selorejo 800-1200 dpl (dari permukaan laut), dan merupakan daerah pegunungan dengan tingkat curah hujan $\pm 100 \mathrm{~mm} /$ tahun. 
Luas hutan 2068,1 ha yang tersebar mengelilingi desa Selorejo. Luas area perkantoran dan sarana rekreasi seluas 26,6 ha. Luas pemukiman $\pm 39,5$ ha dan luas area pertanian 410,47 ha terdiri dari tanah pertanian, ladang, serta peternakan. Produk pertanian yang utama yaitu jeruk. Bahkan jeruk Selorejo terkenal kemanisannya dan kandungan gizinya yang tinggi.

\section{Gambar 1: Peta Lokasi dan Denah Desa Selorejo, Kec. Dau, Malang}

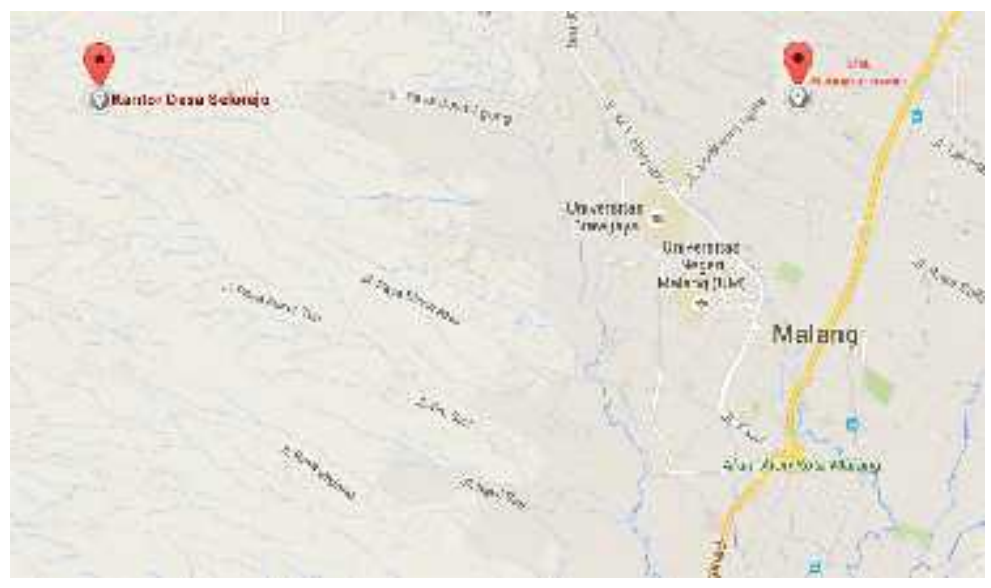

\section{Potensi Desa Selorejo, Malang}

Pemandangan alam yang indah dengan hamparan perkebunan jeruk rakyat dan adanya aliran sungai serta diujung terlihat pohon-pohon pinus yang menandai kawasan hutan lereng Gunung Kawi. Ditinjau potensi yang ada layaklah Desa Selorejo sebagai desa wisata. Adapun potensi yang dimiliki Desa Selorejo yang dapat dikembangkan yaitu (1) wisata petik jeruk; (2) bumi perkemahan bedengan; (3) area coss; (4) air terjun; (5) wisata bunga; dan (6) wisaa petik sayuran hidroponik.

\section{Tujuan Umum Kegiatan IbDM}

Tujuan umum Program IbDM di Desa Selorejo yaitu (a) Menjadikan desa Selorejo menjadi Desa Wisata untuk Kabupaten Malang melalui pemanfaatan potensi lokal sebagai andalan berkembangnya ekonomi masyarakat, sehingga dapat meningkatkan kesejahteraan masyarakat desa Selorejo dan masyarakat Malang pada umumnya; (b) Meningkatkan jiwa wirausaha masyarakat dengan mengembangkan UKM-UKM yang sudah ada; (c) Meningkatkan kerja sama dan menciptakan sinergi antara Gapoktan, Pengelolah Wisata/Karang Taruna, PKK dan UKM serta 
perangkan desa; (d) Mengurangi tingkat kemiskinan dan menambah lapangan kerja baru bagi yang belum mendapat pekerjaan; dan (d) Mempertahankan potensi budaya dan tari lokal.

\section{Tujuan Khusus Program IbDM}

Adapun tujuan khusus Program IbDM yaitu a) Meningkatkan jiwa wirausaha; b) Meningkatkan nilai ekonomis hasil pertanian dan pemanfaatan potensi alam; c) Meningkatkan peran dan partisipasi aktif UKM, PKK dan lembaga sosial lainnya; dan d) Mempertahankan tarian khas berdirinya desa Selorejo.

Dalam program IbDM ini tim membina tiga kelompok yaitu (a) Gabungan Kelompok Tani (GAPOKTAN); (b) Karang Taruna/Pengelola Wisata (Pokdarwis); dan ibu-ibu yang tergabung dalam Program Kesejahteraan Keluarga (PKK).

\section{Urgensi Permasalahan Prioritas}

Permasalahan Desa Selorejo, Malang yaitu a) Masyarakat masih belum siap menerima kunjungan wisata baik wisata domestik maupun wisata mancanegara; b) Tata ruang desa belum rapi termasuk layout parkir bus dan kendaraan wisata; c) Perlunya sentralisasi penjualan jeruk dan produk olahan jeruk lainnya; d) Pendampingan pemberdayaan warga desa yang mempunyai kamar lebih sebagai tempat penginapan bagi wisatawan; dan e) Kurangnya promosi.

\section{Solusi yang Ditawarkan}

Solusi yang ditawarkan Program IbDM tahun-1 yaitu a) Pelatihan Kewirausahaan, GAPOKTAN, PKK, Karang Taruna/ Pengelola wisata; b) Pemetaan Lokasi Wisata Jeruk; c) Membuat Kios Jeruk dan Produk Unggulan Desa; d) Pembuatan Website; e) Pembuatan saluran air di gubug Petik Jeruk; dan f) Pembuatan gubug Petik Jeruk.

Desa Selorejo perlu bersinergi dengan STIE Malangkuççwara untuk dikembangkan menjadi Desa Percontohan Wisata Petik Jeruk di Indonesia, mencakup aspek pembinaan dan pelatihan bagi masyarakat untuk bisa menerima kunjungan wisata dalam dan luar negeri. Lahan parkir perlu penataan lebih baik, penjualan jeruk dan minuman jeruk, serta makanan lainnya yang terkonsentrasi. Selain itu, perlu adanya promosi desa Selorejo sebagai Desa Wisata Petik Jeruk, sehingga terkenal di Indonesia dan mancanegara.

\section{Metode Pelaksanaan}


Metode pelaksanaan Program Iptek bagi Desa Mitra (IbDM) yang akan dilaksanakan oleh Tim pada tahun ke-I dari 3 tahun kemitraan dapat dilihat pada tabel berikut.

\section{Tabel 1: Metode Pelaksanaan Program IbDM}

\begin{tabular}{|l|l|}
\hline \multicolumn{1}{|c|}{ Penyediaan Fasilitas } & \multicolumn{1}{|c|}{ Imlementasi Ipteks dan Manfaat bagi Masyarakat } \\
\hline $\begin{array}{l}\text { 1. Pelatihan Layanan Prima } \\
\text { 2. Pelatihan Pembuatan Kue dari bahan jeruk }\end{array}$ & $\begin{array}{l}\text { 1. Peningkatan Kualitas Layanan Prima } \\
\text { Masyarakat }\end{array}$ \\
$\begin{array}{l}\text { 3. Pelatihan Akuntansi } \\
\text { 4. Pelatihan Marketing }\end{array}$ & $\begin{array}{l}\text { 2. Peningkatan ketrampilan pembuatan kue } \\
\text { berbahan jeruk. }\end{array}$ \\
$\begin{array}{l}\text { 5. Penyediaan Sarana wisata petik jeruk (gazebo } \\
\text { dan gubuk) }\end{array}$ & $\begin{array}{l}\text { 3. Persiapan untuk pelatihan hardware dan software } \\
\text { akuntansi. }\end{array}$ \\
& $\begin{array}{l}\text { 4. Perluasan pemasaran melalui internet (website) } \\
\text { dan media sosial lainnya. }\end{array}$ \\
\end{tabular}

\section{Hasil dan Pembahasan}

Berdasarkan permasalahan yang dihadapi Desa Selorejo sebagai desa mitra, untuk membentuk Desa Wisata Petik Jeruk dalam program Ipteks Bagi Desa Mitra, target dan luaran tahun ke-1 dapat dilihat pada tabel berikut.

Tabel 2: Target dan Luaran Tahun Ke-I

\begin{tabular}{|c|c|c|}
\hline No & Kelompok dan Kegiatan & Luaran \\
\hline 1 & $\begin{array}{l}\text { GAPOKTAN: } \\
\text { 1. Pelatihan Layanan Prima } \\
\text { 2. Pelatihan Marketing } \\
\text { 3. Membuat Kios tempat menjual Jeruk dan } \\
\text { Produk Unggulan Desa. } \\
\text { 4. Pembuatan gubug Petik Jeruk. } \\
\text { 5. Pembuatan saluran air di gubug Petik Jeruk }\end{array}$ & $\begin{array}{l}\text { 1. Pengetahuan mengenai teknik dan strategi pelayanan } \\
\text { prima kepada wisatawan } \\
\text { 2. Ketrampilan memasarkan jeruk dan produk jeruk } \\
\text { 3. Kios/gazebo dibuat dari bambu. } \\
\text { 4. Gubug sederhana yang menampung } 10 \text { orang untuk } \\
\text { mengupas jeruk dan menimbang jeruk hasil } \\
\text { petikannya. } \\
\text { 5. Tersedia saluran air untuk cuci tangan dll }\end{array}$ \\
\hline
\end{tabular}




\begin{tabular}{|c|c|c|}
\hline 2 & $\begin{array}{l}\text { Karang Taruna/ Pokdarwis: } \\
\text { 1. Pelatihan Layanan Prima. } \\
\text { 2. Pelatihan marketing } \\
\text { 3. Pelatihan Kewirausahaan. } \\
\text { 4. Pembuatan website desa wisata petik jeruk } \\
\text { Selorejo. } \\
\text { 5. Pelatihan Akuntansi } \\
\text { 6. Pemetaan Lokasi wisata petik jeruk }\end{array}$ & $\begin{array}{l}\text { 1. Pengetahuan mengenai teknik dan strategi pelayanan } \\
\text { prima kepada wisatawan. } \\
\text { 2. Ketrampilan marketing tradisional dan marketing } \\
\text { berbasis web } \\
\text { 3. Mampu memproduksi minuman sari jeruk dengan } \\
\text { rasa terstandar dan produk kue berbahan jeruk. } \\
\text { 4. Memperkenalkan produk wisata yang jadi unggulan. } \\
\text { 5. Mampu membuat pelaporan keuangan } \\
\text { 6. Tersusunnya master plan lokasi pembangunan sarana } \\
\text { wisata/ anjungan jeruk. }\end{array}$ \\
\hline 3 & $\begin{array}{l}\text { PKK : } \\
\text { 1. Pelatihan Layanan Prima. } \\
\text { 2. Pelatihan marketing } \\
\text { 3. Pelatihan kewirausahaan } \\
\text { 4. Pelatihan Akuntansi }\end{array}$ & $\begin{array}{l}\text { 1. Pengetahuan mengenai teknik dan strategi pelayanan } \\
\text { prima kepada wisatawan. } \\
\text { 2. Ketrampilan memasarkan jeruk dan produk jeruk } \\
\text { 3. Mampu memproduksi minuman sari jeruk dengan } \\
\text { rasa terstandar dan produk kue berbahan jeruk. } \\
\text { 4. Mampu membuat laporan keuangan. }\end{array}$ \\
\hline
\end{tabular}

\section{Hasil dan Luaran yang Dicapai Tahun Ke-I}

Hasil dan Luaran Program IbDM sampai dengan Oktober 2017 telah mencapai 100\% dari target. Adapun kegiatan Program IbDM yang telah dilaksanakan melakukan rapat koordinasi dengan kepala desa untuk menemukan strategi membentuk desa wisaa jeruk, karena sampai saat ini dengan $80 \%$ lahan desa berupa hamparan tanaman jeruk belum difungsikan sevca penuh untuk lebih meningktkn pendapatan masyarakat sevara menyeluruh, dari hasil rapat ini dapat ditemukan skema pengembangan wisara jeruk dalama program pengembangan desa wisata jeruk selama tiga tahun. dapat dilihat pada gambar berikut.

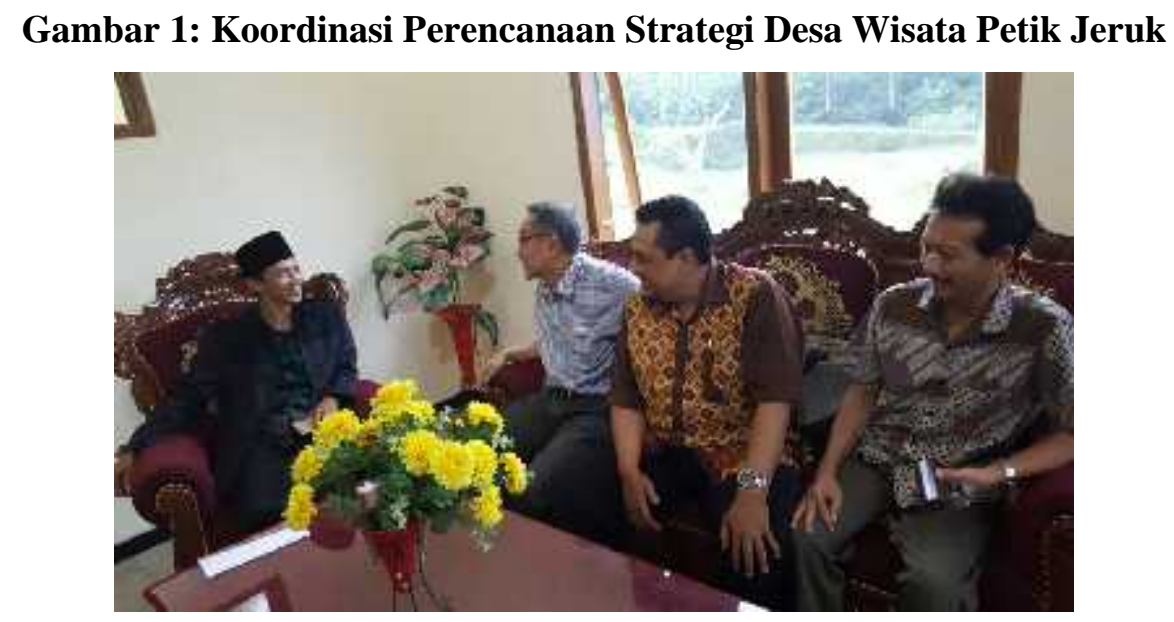


Sesudah rencana tersusun, maka dilakukan koordinasi pembentukan master plan dengan melakukan beberapa kali rapat koordinasi dan pelatihan kepada seluruh tokoh masyarakat, Gabungan Kelompok tani (Gapoktan), anggota asosiasi desa wisata (ASIDEWI), terlihat dalam gambar 2

\section{Gambar 2: Rapat Koordinasi Pembuatan Master Plan Lokasi Sarana Wisata Petik Jeruk}
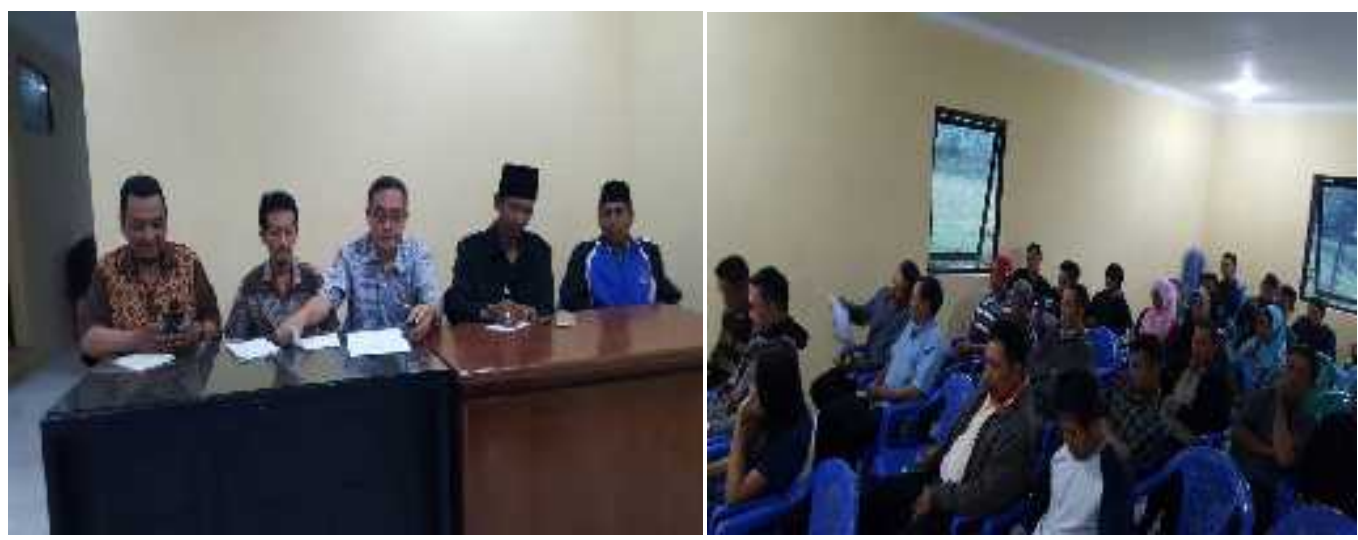

Untuk menghadapi kunjungan wisata juga dilakukan beberapa kali pelatihan bagaimana cara memberi pelayanan kepada tamu wisata agar tamu merasa pusa dengan peayanan masayarakat melalui pelatihan pelayanan prima

\section{Gambar 3: Pelatihan Manajemen Pelayanan Prima}
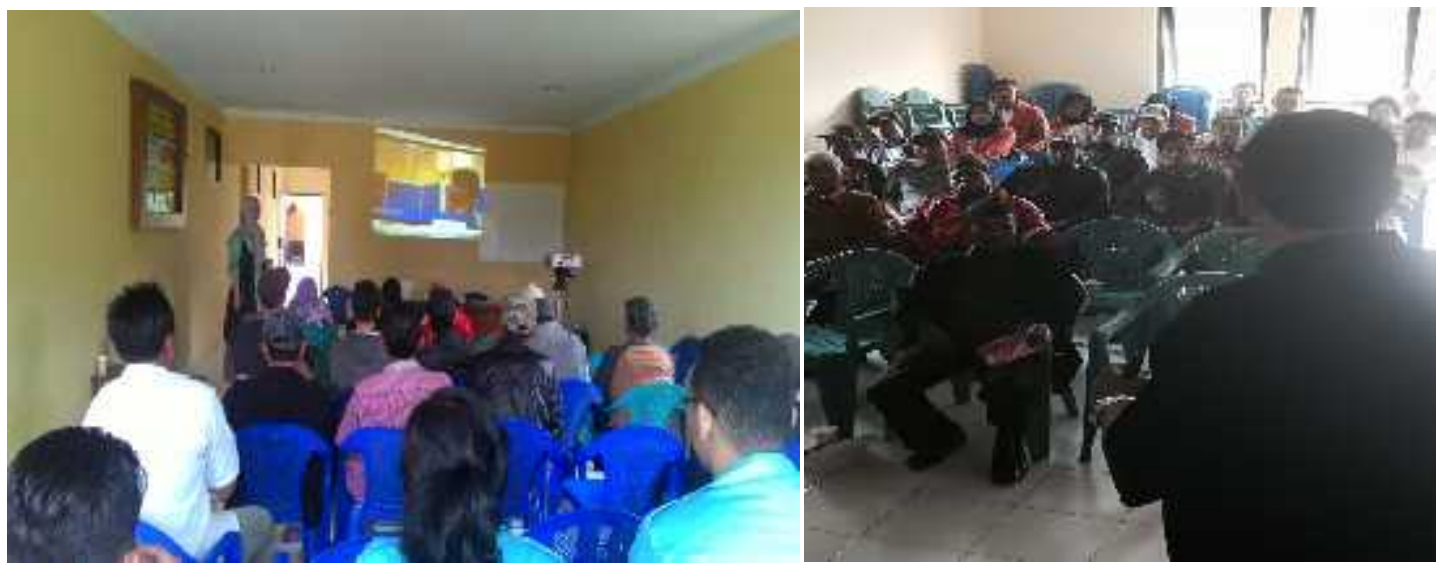

Selain pelayanan prima juga dilakukan pelatihan pembuatan aneka kue dan minuman yang mempunyai cirri khas jeruk sebagai ikon desa wisata jeruk 
Gambar 4: Pelatihan Pembuatan Olahan Makanan Berbahan Jeruk

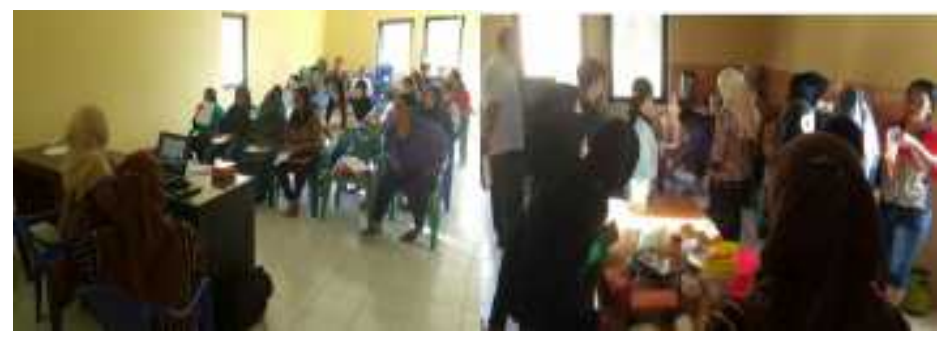

Gambar 5: Hasil Praktek Pembuatan Kue Berbahan Dasar Jeruk
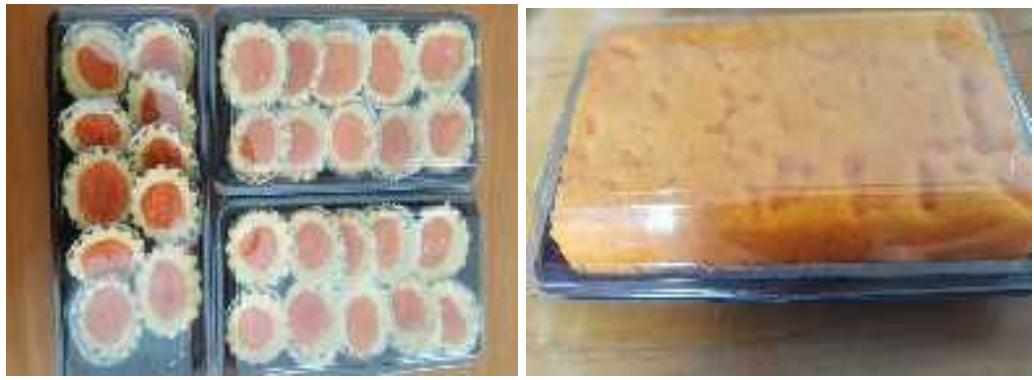

Kepada pelaku wisata juga dilakukan pelatihan akuntansi sederhana agar dapat mengetahui hasil usahanya secara benar, sdfta bagaimana cara memasarkan hasil produknya dikukan pelatihan akuntansi dan marketing

Gambar 6: Pelatihan Akuntansi dan Pelatihan Marketing
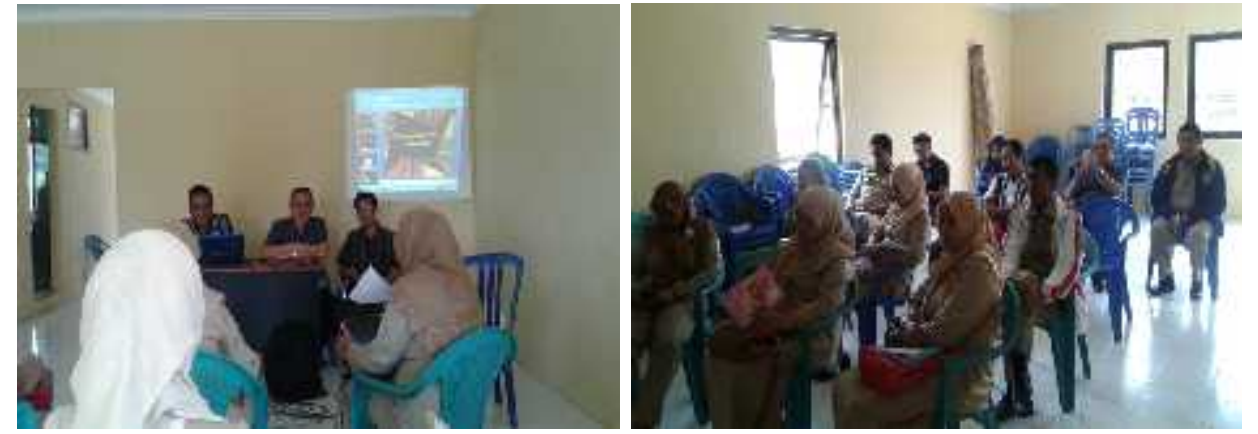
Pada tahun pertama sudah terlihat hasil dari binaan desa wisata yang dilakukan oleh STIE Malangkucecweara dengan bantuan dana sepenuhnya dari Kemenristekdikti, kunjungan wisata sudah terlihat meningkat dan di masing-masing area wisaa petik jeruk sudah tersedia gubuk serta fasilitas cuci tangan yang memadai, selain itu di area parker, di sebeah barat area parker sudah disediakan gazebo untuk menjanjakan produk-produk hasil karya masyarakat,

\section{Gambar 7: Wisatawan Petik Jeruk}
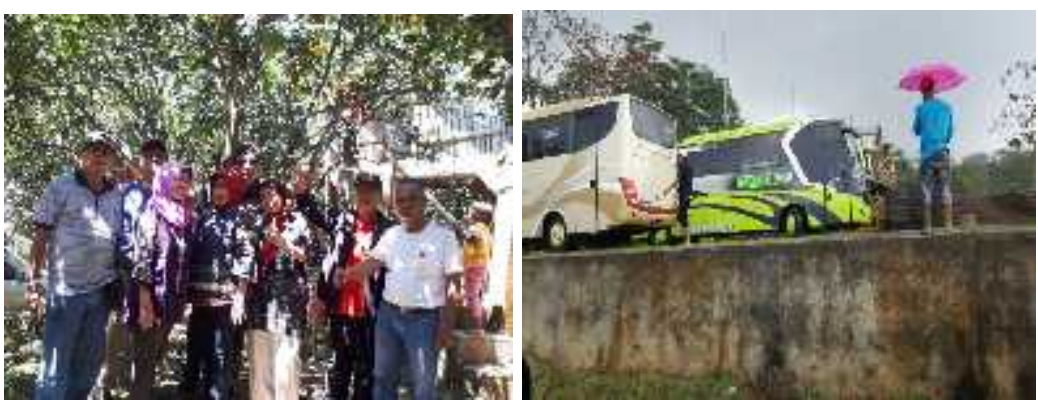

Gambar 8: Gazebo Tempat Penjualan Jeruk dan Hasil Olahan Berbahan Jeruk
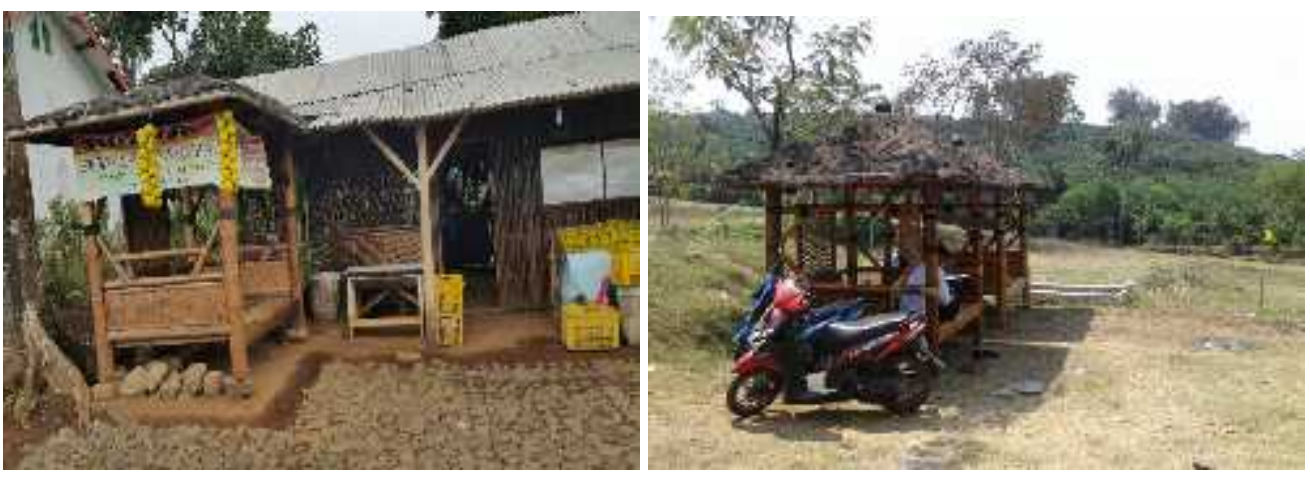

Gambar 9: Gubuk Tempat Wisatawan Menikmati Jeruk
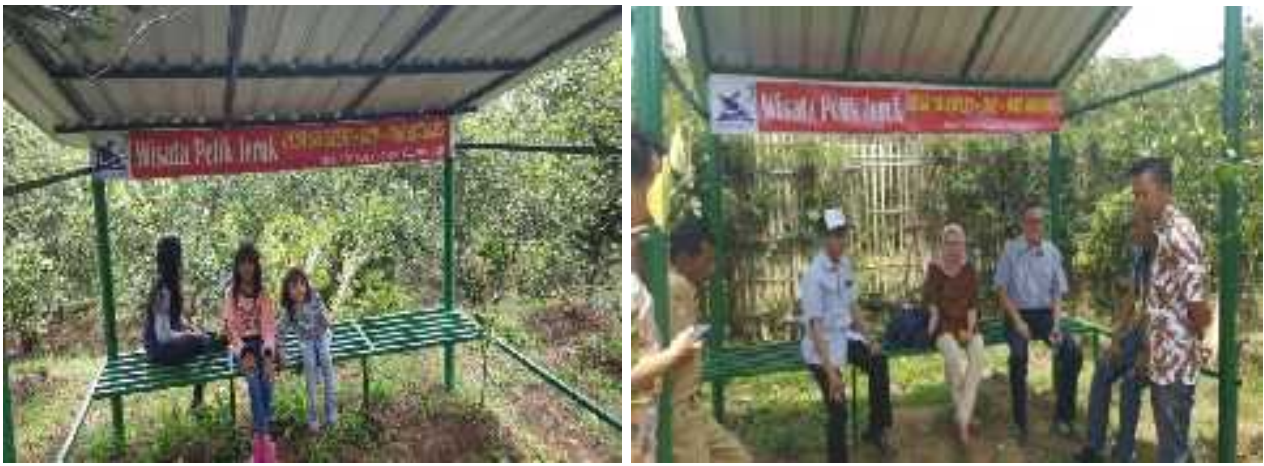


\section{Rencana Program PPDM Tahun Ke-II}

Pada kegiatan berikutnya agar Desa Selorejo menjadi Desa Wisata yang siap menerima kunjungan wisata, sangat perlu untuk melanjutkan Program IbDM atau Program Pengembangan Desa Mitra (PPDM) tahap ke-2.

Sebelum kegiatan dilaksanakan, tim melakuka rapat koordinasi dengan perangkat desa, GAPOKTAN, Karang Taruna/ Pokdarwis dan PKK untuk melakukan evaluasi kegiatan sebelumnya dan menentukan strategi pelaksanaan program yang akan dating.

Adapun rencana kegiatan dan luaran yang akan dilaksanakan pada tahun ke-2 di Desa Selorejo, Malang adalah sebagai berikut: (1) GAPOKTA, Pokdarwis, PKK melakukan pelatihan bahasa Inggris agar mampu berbahasa Inggris dasar untuk menerima kunjungan turis asing; (2) GAPOKTAN dan Pokdarwis memperbaki sarana dan prasarana wisata alam; (3) GAPOKTAN merehabilitasi rumah singgah; (4) Karang Taruna menyediakan tenda camping, membuat icon untuk foto selfi; (5) Karang Taruna dan PKK melakukan pelatihan manajeen perhotelan sederhana.

Rencana kegiatan dan luaran Program Pengembangan Desa Mitra (PPDM) tahun ke-2 dapat dilihat pada tabel 3 .

\section{Rencana Program PPDM Tahun Ke-III}

Bilamana pelaksanaan Program PPDM Desa Wisata Petik Jeruk Selorejo tahun ke-II berhasil dengan baik, besar harapan untuk dilanjutkan pada pelaksanaan Program PPDM tahun ke-III.

Rencana kegiatan dan luaran Program PPDM tahun ke-III dapat dilihat pada tabel 4.

Tabel 3: Rencana Kegiatan dan Luaran PPDM Tahun Ke-II

\begin{tabular}{|c|c|c|}
\hline No & Kelompok dan Kegiatan & Luaran \\
\hline 1 & $\begin{array}{l}\text { GAPOKTAN : } \\
\text { 1. Rehabilitasi rumah singgah } \\
\text { 2. Pelatihan Bahasa Inggris Dasar } \\
\text { 3. Perbaikan sarana dan prasarana wisata } \\
\text { alam }\end{array}$ & $\begin{array}{l}\text { 1. Ketersediaan rumah singgah yang layak huni bagi } \\
\text { wisatawan } \\
\text { 2. Mampu berbahasa Inggris dasar untuk menerima } \\
\text { kunjungan turis asing } \\
\text { 3. Tempat wisata alam yang memenuhi kebersihan } \\
\text { dan kesehatan. }\end{array}$ \\
\hline 2 & $\begin{array}{l}\text { Pengelola Wisata/ Karang Taruna: } \\
\text { 1. Perbaikan sarana dan prasarana wisata } \\
\text { alam }\end{array}$ & $\begin{array}{l}\text { 1. Tempat wisata alam yang memenuhi kebersihan } \\
\text { dan kesehatan } \\
\text { 2. Mampu berbahasa Inggris dasar untuk menerima }\end{array}$ \\
\hline
\end{tabular}




\begin{tabular}{|c|c|c|}
\hline & $\begin{array}{l}\text { 2. Pelatihan Bahasa Inggris Dasar } \\
\text { 3. Penyediaan tenda untuk camping } \\
\text { 4. Dibuatkan sarana ikon untuk foto selfi } \\
\text { 5. Pelatihan manajemen hotel sederhana }\end{array}$ & $\begin{array}{l}\text { kunjungan kunjungan turis asing } \\
\text { 3. Tersedianya tenda sewa untuk bermalam di alam } \\
\text { terbuka /camping } \\
\text { 4. Wisatawan ada tempat berfoto selfi } \\
\text { 5. Pengelola rumah singgah mempunyai keahlian } \\
\text { dalam mengelola dan melayani wisatawan yang } \\
\text { bermalam di lokasi }\end{array}$ \\
\hline 3 & $\begin{array}{l}\text { PKK : } \\
\text { 1. Pelatihan bahasa Inggris sederhana } \\
\text { 2. Pelatihan manajemen hotel sederhana }\end{array}$ & $\begin{array}{l}\text { 1. Mampu berbahasa Inggris dasar untuk menerima } \\
\text { kunjungan turis asing } \\
\text { 2. Pengelola rumah singgah mempunyai keahlian } \\
\text { dalam mengelola dan melayani wisatawan yang } \\
\text { bermalam di lokasi. }\end{array}$ \\
\hline
\end{tabular}

Tabel 4: Rencana Kegiatan dan Luaran PPDM Tahun Ke-III

\begin{tabular}{|c|c|c|}
\hline No & Kelompok dan Kegiatan & Luaran \\
\hline 1 & $\begin{array}{l}\text { GAPOKTAN: } \\
\text { Perbaikan Sarana dan prasarana pendukung } \\
\text { wisata }\end{array}$ & Perbaikan kios dan jalan penghubung antar kios \\
\hline 2 & $\begin{array}{l}\text { Pengelola Wisata/ Karang Taruna: } \\
\text { 1. Pelatihan tari } \\
\text { 2. Pembuatan film dukumentasi desa wisata } \\
\text { petik jeruk } \\
\text { 3. Penyempurnaan website } \\
\text { 4. Membuat buku panduan wisata }\end{array}$ & $\begin{array}{l}\text { 1. Tim penari untuk menyambut rombongan } \\
\text { wisatawan } \\
\text { 2. Film dokumentasi Desa Wisata Untuk diputar } \\
\text { dalam rangkaian Selamat datang rombongan } \\
\text { wisatawan } \\
\text { 3. Informasi lengkap tentang keberadaan Desa } \\
\text { Wisata Petik Jeruk } \\
\text { 4. Hard book berisi panduan lengkap tentang Desa } \\
\text { Wisata Petik Jeruk Selorejo Malang }\end{array}$ \\
\hline 3 & $\begin{array}{l}\text { BUMDes: } \\
\text { Pelatihan Manajemen dan Akuntansi }\end{array}$ & $\begin{array}{l}\text { BUMDes yang mampu memanaj usaha desa dan } \\
\text { mampu membuat laporan keuangan. }\end{array}$ \\
\hline
\end{tabular}

Dari tabel 4 dapat dijelaskan bahwa rencana kegiatan dan luaran tahun ke-III adalah (1) GAPOKTAN melakukan kegiatan perbaikan kios dan jalan penghubung antar kios; (2) Pengelola Wisata/Karang Taruna melakukan pelatihan tari untuk menyambut rombongan wisatawan; (3) Pengelola Wisata/Karang Taruna melakukan pembuatan film dukumentasi Desa Wisata Petik 
Jeruk Selorejo dalam rangkaian selamat datang rombongan wisatawan; (4) Pengelola Wisata/Karang Taruna melakukan penyempurnaan website dan buku panduan wisatawan yang berisi informasi lengkat tetang desa wisata petik jeruk Selorejo; dan (5) BUMDes melakukan pelatihan manajemen dan akuntansi agar BUMDes mampu memanaj usaha desa dan membuat laporan keuangan dengan baik.

\section{Kesimpulan dan Saran-saran}

\section{Kesimpulan}

1. Perlu adanya sinergi antar lembaga di Desa Selorejo, seperti PKK, Gapoktan, Karang Taruna/Pengelolah Wisata (Pokdarwis), dan tokoh masyarakat untuk saling membantu berkerjasama dalam mewujudkan Desa Selorejo sebagai Desa Wisata Petik Jeruk.

2. Potensi tanaman jeruk di Desa Selorejo sangat potensial dan petani menjualnya secara langsung berupa buah jeruk. Untuk meningkatkan added value perlu dibuat kue dan minuman sari jeruk, di sini tim IbDM mengadakan pelatihan pembuatan kue dan minuman berbahan dasar jeruk.

3. Perangkat desa, lembaga social seperti PKK, Karang Taruna/Pokdarwis, GAPOKTAN perlu pengetahuan tentang tatacara penerima kunjungan wisatawan, maka tim IbDM melakukan kegiatan pelatihan pelayanan prima.

4. Untuk memperkenalkan Selorejo sebagai desa wisata secara intensif dengan melibatkan banyak pihak, tim melakukan pelatihan kepada perangkat desa, Karang Taruna/Pokdarwis, GAPOKTAN dan PKK.

5. Diperlukan promosi memperkenalkan Selorejo sebagai desa wisata petik jeruk secara luas, tim IbDM membuatkan website agar masyarakat mengetahui informasi lebih lengkap, dan diharapkan menarik pengunjung wisatawan.

6. Untuk menertibkan pembukuan dari semua lembaga yang terlibat dalam pengelolahan keuangan, tim IbDM melakukan pelatihan akuntansi dan pendampingan pembuatan laporan keuangan kepada Karang Taruna/Pengelola Wisata, PKK dan perangkat desa.

7. Agar supaya pengunjung petik jeruk merasa nyaman, tim IbDM membantu membuatkan gubug/rumah singgah sederhana dan tempat cuci tangan. 
8. Direncanakan adanya sentralisasi penjualan jeruk dan produk olahan berbahan jeruk, Tim IbDM membantu membuat kios tempat penjualan produk tersebut.

\section{Saran-saran}

1. Lembaga-lembaga yang ada di desa Selorejo yang dipimpin Kepala Desa beserta masyarakat harus inovatif dan mempunyai kemauan keras untuk mewujudkan Selorejo sebagai desa wisata petik jeruk.

2. Perlu adanya fasilitas pelengkap wisata seperti kolam renang, tempat bermain anak-anak, tour keliling kebun jeruk, icon untuk berfoto selfi, dan kebun sayur hidroponik. Sehingga pada waktu jeruk belum berbuah, wisatawan masih bisa menikmati sarana rekreasi yang lain.

\section{Daftar Pustaka}

Aviliani. 2013. Industri Kreatif dan Properti Makin Pesat di Malang. Jawa Pos, 20 April 2013.

Djawahir. Helmy Achmad. 2012. Penglolaan dan Pengembangan UMKM Indonesia. Bahan Semiloka Puskabang UMKM dan KKM FEB Universitas Brawijaya. Malang.

Kusnanto, A.A dan Hadi, S. 2014. Kepedulian Perguruan Tinggi Terhadap Pengusaha Kecil Melalui Bantuan Sarana Produksi, Teknologi Informasi dan Pelaporan Keuangan. Jurnal ABM-Mengabdi, Volume 1, Desember 2014.

Kusnanto, A. A dan Supriyanto. 2015. Kemitraan Perguruan Tinggi dengan UKM untuk Meningkatkan Kapasitas Produksi Melalui Bantuan Sarana Produksi, Teknologi Informasi dan Pendampingan Pembuatan Laporan Keuangan. Jurnal ABM Mengabdi, Vol. 2, Desember 2015. ISSN: 2477-6432.

Lukman, Adhi S. 2013. UKM Makanan dan Minuman Belum Memiliki Trik Canggih Dalam Marketing. Artikel. 